\title{
Evolução anual da qualidade do leite cru refrigerado processado em uma indústria de Minas Gerais
}

\author{
[Annual evolution of raw milk quality processed in a dairy industry of \\ Minas Gerais state, Brazil] \\ C.A.V. Paiva ${ }^{1}$, M.M.O.P. Cerqueira ${ }^{2}$, M.R.S. Souza ${ }^{2}$, A.M.Q. Lana ${ }^{2}$
}

\begin{abstract}
${ }^{1}$ Aluno de pós-graduação - Escola de Veterinária - Universidade Federal de Minas Gerais - Belo Horizonte, MG ${ }^{2}$ Escola de Veterinária- Universidade Federal de Minas Gerais - Belo Horizonte, MG
\end{abstract}

\section{RESUMO}

Analisou-se a evolução anual da qualidade de leite cru refrigerado pelo levantamento e análise estatística do banco de dados das análises individuais de leite dos tanques refrigeradores, computadas mensalmente entre abril de 2002 e dezembro de 2008 em uma indústria de Minas Gerais. O volume de leite em conformidade com a IN51 para contagem bacteriana total para o ano de 2008 aumentou de 74,3\% em 2002 para $85,8 \%$ em 2008. Considerando-se a IN51 para o ano de 2011, esses valores seriam de $30,5 \%$ e $46,6 \%$, respectivamente. O volume de leite em conformidade com a IN51 para contagem de células somáticas reduziu-se de 93,5\% em 2002 para 90,1\% em 2008. Para o ano de 2011, esses valores seriam de 64,9 e 60,5\%, respectivamente. Em relação à composição sólida do leite, o volume de leite em conformidade com a IN51 para os teores de gordura, de proteína e de extrato seco desengordurado foi de $95,2 \%, 98,2 \%$ e $89,6 \%$, respectivamente. As variações sazonais influenciaram a qualidade do leite cru refrigerado de tanques de expansão. A implantação de um sistema de pagamento por qualidade do leite ao produtor foi eficaz na melhoria dos índices de qualidade da matéria-prima.

Palavras-chave: leite, IN 51, contagem bacteriana total, células somáticas, composição sólida, pagamento por qualidade

\begin{abstract}
The present study aimed to analyze the annual evolution of cooled raw milk quality, through analytical analysis of the data base of individual bulk milk tanks analysis, monthly computed from April/2002 to December/2008 at a dairy industry in Minas Gerais. The mean volume of milk in compliance with IN51 for total bacterial count for year 2008 increased from $74.3 \%$ in 2002 to $85.8 \%$ in 2008. Considering IN51 for year 2011, these values would be $30.5 \%$ and $46.6 \%$, respectively. The mean volume of milk in compliance with IN51 for somatic cells count reduced from $93.5 \%$ in 2002 to $90.1 \%$ in 2008. Considering the legal standard for the year of 2011, these values would be 64.9 and $60.5 \%$, respectively. In relation to the solid composition of milk, the mean volume of milk in compliance with IN51 for fat, protein and solids nonfat were $95.2 \%, 98.2 \%$ and $89.6 \%$, respectively. The season variations affected the quality of the bulk tank cooled raw milk from bulk tanks. The implantation of a payment system for the quality of milk to the producer revealed to be efficient in its objective to improve the quality indexes of raw milk.
\end{abstract}

Keywords: milk, IN 51, total bacterial and somatic cell count, composition, quality payment

\section{INTRODUÇÃO}

A cadeia produtiva do leite no Brasil é um dos setores mais importantes para a economia do país, gerando empregos para milhões de brasileiros (Alvim et al., 2002). A produção de leite é uma das poucas atividades do setor rural que gera renda mensal e contribui para a diminuição do êxodo rural do homem do campo. O leite é importante na produção de alimentos na maioria dos países do mundo, pois apresenta alto valor nutricional e é indispensável para a dieta do ser humano.

Recebido em 16 de março de 2011

Aceito em 12 de janeiro de 2012

E-mail: caversianipaiva@gmail.com 
Com o aumento da população mundial nas últimas décadas, principalmente nos países em desenvolvimento, e a recente diminuição dos estoques de leite em pó da Europa e a menor produção de leite por países tradicionais, como, por exemplo, Nova Zelândia e Austrália, devido a problemas climáticos, a balança oferta/demanda de leite abre uma nova perspectiva ao Brasil. Esse novo cenário contribui para o desenvolvimento da cadeia produtiva do leite no país, fazendo com que o setor comece a avançar em um ritmo mais rápido.

A profissionalização do setor é uma tendência no atual mundo globalizado, que exige qualidade de forma compulsória. No Brasil, antes da implantação da Instrução Normativa $n^{\circ} 51$ (IN 51), a qualidade do leite não era monitorada por critérios utilizados internacionalmente. A partir desta data, no entanto, parâmetros internacionais de qualidade, como contagem bacteriana total (CBT) e de células somáticas (CCS), determinação dos teores de proteína, gordura, extrato seco desengordurado (ESD) e extrato seco total (EST), passaram a ser avaliados (Brasil, 2002). Com este monitoramento, as indústrias de laticínios no país passaram a ter bancos de dados com informações importantes sobre variações sazonais que influenciam no teor de sólidos, no rendimento industrial $\mathrm{e}$ ainda na competitividade frente a mercados internacionais. Analisar criticamente estas informações que são geradas pelos laboratórios oficiais da Rede Brasileira de Laboratórios de Análise da Qualidade do Leite (RBQL) é fundamental para estabelecer políticas de melhoria da qualidade do leite no país.

Considerando-se tais aspectos, o presente trabalho se propôs a analisar a qualidade do leite cru refrigerado de um laticínio de Minas Gerais no período de abril/2002 a dezembro/2008 e avaliar criticamente o impacto da implantação do pagamento do leite por qualidade.

\section{MATERIAL E MÉTODOS}

Foram analisadas 60.243 amostras de leite de tanques refrigeradores individuais de produtores pertencentes à bacia leiteira do município de Guanhães, Minas Gerais. Os parâmetros analisados incluíram: CBT e CCS e determinação dos teores de gordura, de proteína e de extrato seco desengordurado do leite. As análises para determinação da composição do leite (International..., 2000) e a contagem de células somáticas (International..., 1995) foram realizadas em equipamento eletrônico (Bentley CombSystem 2300, Bentley Instruments ${ }^{\circledR}$ ) pelo princípio de absorção de comprimento de onda no infravermelho e citometria de fluxo, respectivamente. A contagem bacteriana total foi feita em equipamento eletrônico (Bactocount IBC 150 , Bentley Instruments ${ }^{\circledR}$ ) pelo princípio de citometria de fluxo, segundo recomendações do fabricante.

As análises foram realizadas mensalmente entre abril de 2002 e dezembro de 2008, seguindo as exigências legais da Instrução Normativa n.51 do Ministério da Agricultura, Pecuária e Abastecimento (MAPA). As amostras de leite foram acondicionadas em frascos plásticos esterilizados de $50 \mathrm{~mL}$ contendo um comprimido de bronopol para determinação da CBT e um comprimido de azidiol para determinação da CCS e composição centesimal. Após a coleta, as amostras foram transportadas em condições isotérmicas em caixas contendo gelo reciclável até o chegada ao laboratório.

Os resultados obtidos foram submetidos à análise descritiva, utilizando-se o software Statistical Analysis for Windows ${ }^{\circledR}$, e a comparação das frequências observadas (CBT, CCS, teores de gordura, proteína e extrato seco desengordurado) foi feita pelo teste do qui-quadrado, utilizando-se o software GraphPad InStat ${ }^{\circledR}$. Todos os resultados foram comparados seguindo o método de grupamento dois a dois para a análise de significância estatística do teste (Sampaio, 2002). $\mathrm{O}$ estudo de frequência das amostras foi tabulado em função da sazonalidade (Souza et al., 2003; Souza et al., 2006; Tonello et al., 2009), comparando-se os dados de qualidade do leite em conformidade com os padrões legais da IN51 para o ano de 2008 e a partir de 2011. Nas análises temporais, a implantação do sistema de pagamento do leite a partir de 2005 e seu efeito sobre a qualidade do leite foram também considerados.

\section{RESULTADOS E DISCUSSÃO}

Verificou-se aumento significativo na média de leite captada/produtor/mês e no volume de leite recebido pela indústria em conformidade com a 
IN51 para os parâmetros de CBT estabelecidos para 2008 e 2011 (Tab. 1 e 2). Este aumento foi mais significativo a partir de 2005 (Fig. 1 e 2), quando a indústria implantou o programa de pagamento por qualidade. Os sistemas de pagamento por qualidade visando à melhoria da qualidade do leite foram adotados por diversos países desenvolvidos que atingiram elevados padrões de qualidade microbiológica do leite (Machado, 2008). As ações para a melhoria da contagem bacteriana do leite são relativamente simples, porém necessitam de atenção constante nos procedimentos adotados. Ações relacionadas à higiene do úbere e à correta rotina de ordenha (Galton, 1986), além da limpeza adequada do equipamento de ordenha (Wong, 1988), constituem os principais fatores para a obtenção higiênica do leite.

Os resultados deste estudo mostraram a importância da implantação do sistema de pagamento por qualidade para a melhoria da qualidade microbiológica do leite. Normalmente a diminuição da contagem bacteriana total do leite é o primeiro parâmetro de qualidade a ser alcançado pelo produtor, em razão da maior facilidade na implantação das mudanças necessárias, do baixo custo despendido para adequação das medidas corretivas e da remuneração obtida dentro do sistema de pagamento pela qualidade.

Em vista dos padrões legais para 2011, verificase a necessidade de revisão dos componentes do sistema de pagamento por qualidade para a CBT, além de ações de extensão para aumentar o nível de conhecimento e conscientização do produtor de leite. A melhoria da qualidade do leite terá reflexos na maior inserção dos produtos lácteos brasileiros em mercados mais exigentes, como, por exemplo, a União Europeia. A elevada CBT coloca em risco a saúde dos consumidores pela provável veiculação de doenças e, para a indústria, ocasiona prejuízos relacionados a defeitos sensoriais nos derivados lácteos (Mendonça et al., 2001). Hoje, os maiores entraves ao aumento das exportações brasileiras de derivados lácteos são a presença de resíduos e contaminantes e a qualidade microbiológica da matéria-prima.

Tabela 1. Resultados anuais médios de contagem bacteriana total (CBT) do leite captado por uma indústria de Minas Gerais, no período de 2002 a 2008, em conformidade com os padrões legais da IN 51 para 2008 e 2011

\begin{tabular}{|c|c|c|c|c|c|c|c|c|}
\hline \multirow{3}{*}{ Ano } & \multicolumn{8}{|c|}{ Contagem bacteriana total } \\
\hline & \multicolumn{4}{|c|}{ Padrão $2008(\leq 750.000 \mathrm{UFC} / \mathrm{mL})$} & \multicolumn{4}{|c|}{ Padrão $2011(\leq 100.000 \mathrm{UFC} / \mathrm{mL})$} \\
\hline & $\begin{array}{c}\text { Captação média } \\
\text { (litros/produtor/mês) }\end{array}$ & $\begin{array}{c}\text { CBT (log } \\
\text { UFC+1/mL) }\end{array}$ & $\mathrm{N}$ & $\%$ & $\begin{array}{c}\text { Captação média } \\
\text { (litros/produtor/mês) }\end{array}$ & $\begin{array}{c}\text { CBT (log } \\
\text { UFC }+1 / \mathrm{mL})\end{array}$ & $\mathrm{N}$ & $\%$ \\
\hline 2002 & 5923 & 5,20 & $3324^{\mathrm{a}}$ & 63,54 & 6303 & 4,68 & $1237^{\mathrm{a}}$ & 23,65 \\
\hline 2003 & 6129 & 5,17 & $5034 \mathrm{~b}$ & 60,05 & 6300 & 4,70 & $2118 b$ & 25,27 \\
\hline 2004 & 6084 & 5,21 & $4855 b$ & 61,27 & 6297 & 4,72 & $1816^{\mathrm{a}}$ & 22,92 \\
\hline 2005 & 6831 & 5,21 & $5079 b$ & 60,49 & 7427 & 4,69 & $1870^{\mathrm{a}}$ & 22,27 \\
\hline 2006 & 6692 & 5,10 & $6964 c$ & 74,25 & 7078 & 4,62 & $3078 \mathrm{c}$ & 32,82 \\
\hline 2007 & 6244 & 5,08 & $8403 d$ & 80,87 & 6871 & 4,63 & $3632 d$ & 34,95 \\
\hline 2008 & 6995 & 5,10 & $8439 d$ & 80,08 & 7808 & 4,64 & $3505 \mathrm{c}$ & 33,26 \\
\hline Total & 6482 & 5,14 & 42098 & 69,88 & 6987 & 4,66 & 17256 & 28,64 \\
\hline
\end{tabular}

Valores seguidos de letras minúsculas distintas na coluna indicam diferença significativa $(\mathrm{P} \leq 0,05)$, pelo teste do quiquadrado.

No período de 2002 a 2008, a contagem de células somáticas apresentou-se estável, com tendência de discreta redução a partir de 2002 (Tab. 2). Isto pode estar relacionado ao fato de a maioria dos produtores não realizarem monitoramento da CCS individual do leite das vacas. Sem este monitoramento, torna-se difícil controlar a mastite subclínica, usualmente causada por patógenos contagiosos que se disseminam rapidamente no rebanho. Outro ponto importante refere-se ao baixo número de produtores que realiza tratamento de vaca seca. Estas estratégias são extremamente eficazes para o controle da mastite e dos patógenos associados à mastite contagiosa (Santos e Fonseca, 2007). Além disto, os resultados observados demonstraram que a implantação do programa de pagamento por qualidade do leite em julho de 2005 não foi suficiente, por si só, para reverter essa tendência (Fig. 2). 
Tabela 2. Resultados anuais médios de contagem de células somáticas (CCS) do leite captado por uma indústria de laticínios de Minas Gerais, no período de 2002 a 2008, em conformidade com os padrões legais da IN 51 para 2008 e 2011

\begin{tabular}{|c|c|c|c|c|c|c|c|c|}
\hline \multirow{3}{*}{ Ano } & \multicolumn{8}{|c|}{ Contagem de células somáticas } \\
\hline & \multicolumn{4}{|c|}{ Padrão 2008 ( $\leq 750.000$ céls $/ \mathrm{mL})$} & \multicolumn{4}{|c|}{ Padrão 2011 ( $\leq 400.000$ céls $/ \mathrm{mL}$ ) } \\
\hline & $\begin{array}{c}\text { Captação média } \\
\text { (litros/produtor/mês) }\end{array}$ & $\begin{array}{l}\text { CCS (log } \\
\text { céls }+1 / \mathrm{mL})\end{array}$ & $\mathrm{N}$ & $\%$ & $\begin{array}{c}\text { Captação média } \\
\text { (litros/produtor/mês) }\end{array}$ & $\begin{array}{c}\text { CCS }(\log \\
\text { céls }+1 / \mathrm{mL})\end{array}$ & $\mathrm{N}$ & $\%$ \\
\hline 2002 & 5693 & 5,41 & $4878^{\mathrm{a}}$ & 93,25 & 5342 & 5,30 & $3584^{\mathrm{a}}$ & 68,51 \\
\hline 2003 & 5988 & 5,40 & $7716 \mathrm{~b}$ & 92,04 & 5454 & 5,29 & $5762^{\mathrm{a}}$ & 68,73 \\
\hline 2004 & 6007 & 5,41 & $7203 c$ & 90,90 & 5226 & 5,29 & $5257 b$ & 66,34 \\
\hline 2005 & 7708 & 5,39 & $7693 \mathrm{bc}$ & 91,62 & 6719 & 5,28 & $5805^{\mathrm{a}}$ & 69,13 \\
\hline 2006 & 6587 & 5,43 & $8658 b$ & 92,31 & 5839 & 5,33 & $6353^{\mathrm{a} b}$ & 67,74 \\
\hline 2007 & 6046 & 5,45 & $9431 d$ & 90,76 & 5361 & 5,33 & $6539 \mathrm{c}$ & 62,93 \\
\hline 2008 & 6891 & 5,45 & $9575 \mathrm{~cd}$ & 90,86 & 6109 & 5,33 & $6766 c$ & 64,21 \\
\hline Total & 6465 & 5,42 & 55154 & 91,55 & 5754 & 5,31 & 40066 & 66,51 \\
\hline
\end{tabular}

Valores seguidos de letras minúsculas distintas na coluna indicam diferença significativa $(\mathrm{P} \leq 0,05)$, pelo teste do quiquadrado.

O sistema de pagamento para CCS considerou até o ano de 2008 apenas os componentes de bonificação e neutralidade. Isso explica, em parte, a estabilidade dos índices de frequência de amostras conformes após a implantação do programa de pagamento por qualidade. $\mathrm{O}$ produtor de leite fora dos padrões legais que não era bonificado acomodava-se com a situação por não sofrer a penalização. O reflexo disto poderá ser notado a partir de 2011, quando a frequência de amostras conformes terá uma redução brusca. Será necessária a adoção de uma nova tabela de pagamento que contemple os três componentes de sustentação do programa: bonificação, neutralidade e desconto para que as ações por parte da indústria e dos produtores se tornem mais eficazes do que são hoje. Programas integrados de melhoria da sanidade, genética e nutrição animal devem ser elaborados e implantados para suportar tais mudanças.

O percentual de volume de leite em conformidade com a IN51 para CCS também seguiu a mesma tendência da frequência de amostras. Para o ano de 2008, o percentual de volume de leite em conformidade com a IN51 reduziu-se de 93,5\% (93,2\% das amostras) em 2002 para 90,1\% (90,9\% das amostras) em 2008. Considerando-se o padrão legal para 2011, esses valores seriam de 64,9 (68,5\% das amostras) e $60,5 \%(64,2 \%$ das amostras), respectivamente (Fig. 2).
Em relação ao mercado internacional, a CCS também poderá representar uma barreira não tarifária aos produtos lácteos nacionais a partir do ano de 2011. A CCS constitui um critério de análise do leite cru, uma vez que a vaca com mastite produz leite com composição alterada, o que resulta em produtos de baixa qualidade (Gigante e Costa, 2008), além de afetar o rendimento de fabricação de diversos derivados lácteos (Santos e Fonseca, 2007). É preciso iniciar uma mudança imediata para que o atual volume de leite em conformidade com a IN51 para o marco legal do ano de 2011 seja elevado aos patamares do ano de 2008. Por se tratar de um parâmetro de evolução lenta e que normalmente envolve custos elevados na adoção de ações corretivas, tais como descarte de animais, medicamentos para tratamento da mastite clínica e assistência técnica veterinária, a contagem de células somáticas constitui, hoje, um dos principais desafios da melhoria da qualidade do leite no curto prazo.

A frequência de amostras em conformidade com a IN51, para os parâmetros de composição sólida do leite computada pela média anual ao longo do período de 2002 a 2008, vem apresentando uma estabilidade desde o ano de 2002 (Tab. 3 e 4). Esse fato demonstra que o programa de pagamento por qualidade do leite não foi suficiente para reverter essa tendência. 

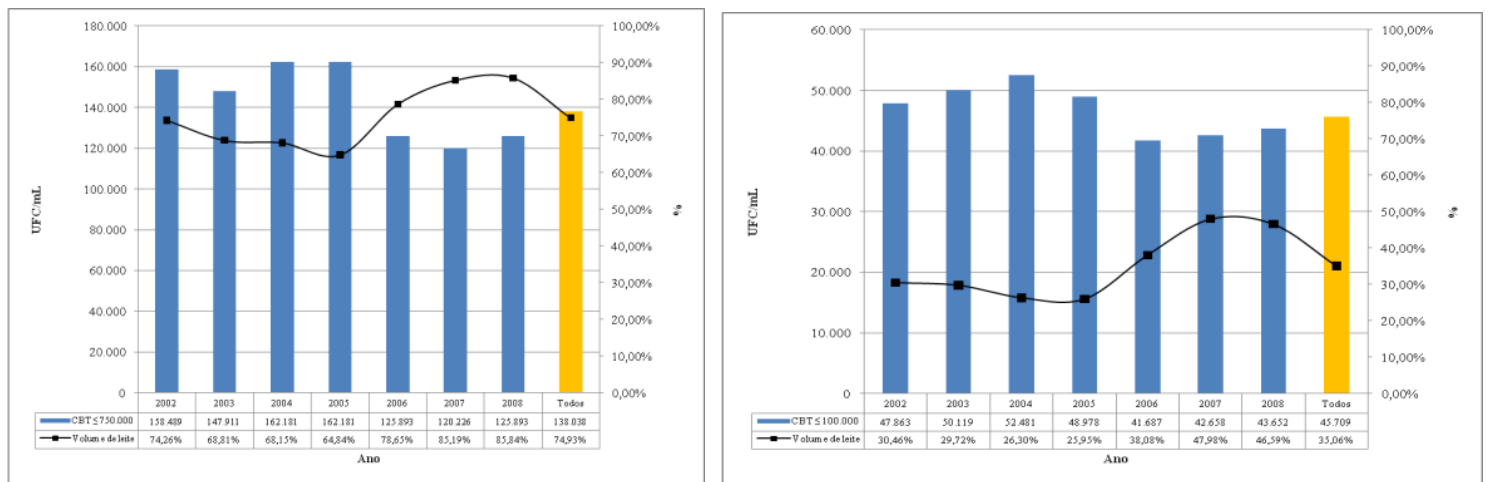

Figura 1. Volume percentual anual de leite captado por uma indústria de Minas Gerais, no período de 2002 a 2008, com valores médios de contagem bacteriana total (média geométrica), em conformidade com os padrões legais da IN 51 para 2008 e 2011.

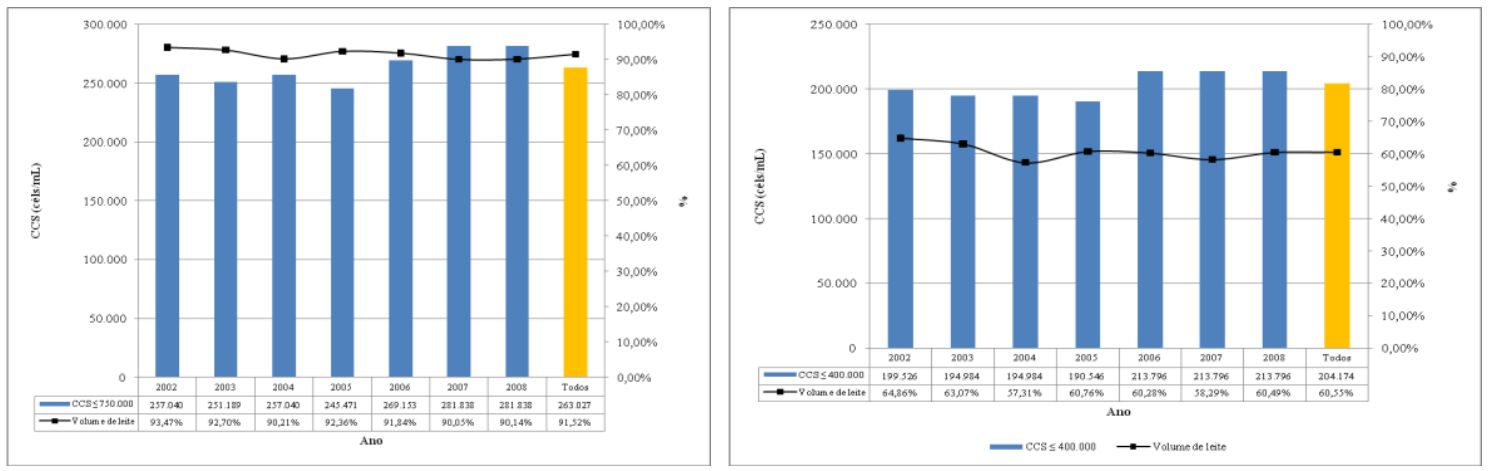

Figura 2. Volume percentual anual de leite captado por uma indústria de Minas Gerais, no período de 2002 a 2008, com valores médios de contagem de células somáticas (média geométrica), em conformidade com os padrões legais da IN 51 para 2008 e 2011.

Tabela 3. Resultados anuais médios de teor de gordura do leite captado por uma indústria de laticínios de Minas Gerais, no período de 2002 a 2008, em conformidade com os padrões legais da IN 51

\begin{tabular}{|c|c|c|c|c|c|c|c|c|}
\hline \multirow{3}{*}{ Ano } & \multicolumn{4}{|c|}{ Teor de gordura } & \multicolumn{4}{|c|}{ Teor de proteína } \\
\hline & \multicolumn{4}{|c|}{$>3,00 \%$} & \multicolumn{4}{|c|}{$>2,90 \%$} \\
\hline & $\begin{array}{c}\text { Captação média } \\
\text { (litros/produtor/mês) }\end{array}$ & Média & $\mathrm{N}$ & $\%$ & $\begin{array}{c}\text { Captação média } \\
\text { (litros/produtor/mês) }\end{array}$ & Média & $\mathrm{N}$ & $\%$ \\
\hline 2002 & 5793 & 3,73 & $4914 a$ & 93,94 & 5756 & 3,26 & $5079^{a}$ & 97,09 \\
\hline 2003 & 6097 & 3,74 & $7763 b$ & 92,60 & 6001 & 3,26 & $8097 \mathrm{ac}$ & 96,59 \\
\hline 2004 & 6209 & 3,74 & 7393ab & 93,30 & 6132 & 3,31 & $7828 b$ & 98,79 \\
\hline 2005 & 7886 & 3,70 & $7870 \mathrm{a}$ & 93,72 & 7738 & 3,29 & $8222 d$ & 97,92 \\
\hline 2006 & 6748 & 3,72 & $8990 \mathrm{c}$ & 95,85 & 6693 & 3,28 & 9194d & 98,03 \\
\hline 2007 & 6169 & 3,70 & $9752 \mathrm{a}$ & 93,85 & 6189 & 3,25 & $9983 c$ & 96,07 \\
\hline 2008 & 7021 & 3,72 & $9884 a$ & 93,79 & 7046 & 3,32 & $10407 \mathrm{~b}$ & 98,76 \\
\hline Total & 6611 & 3,72 & 56566 & 93,90 & 6565 & 3,28 & 58810 & 97,62 \\
\hline
\end{tabular}

Valores seguidos de letras minúsculas distintas na coluna indicam diferença significativa $(\mathrm{P} \leq 0,05)$, pelo teste do quiquadrado.

O percentual de volume de leite em conformidade com a IN51 para o teor de gordura apresentou discreto aumento entre os anos de 2002 e 2006 e uma redução nos anos de 2007 a 2008. A gordura constitui o componente que sofre a maior variação no leite, influenciada por fatores ambientais, de manejo (especialmente pela nutrição) e genéticos (Reis et al., 2004). Em relação ao teor de proteína, o volume de leite manteve-se estável (Fig. 3). Variações nos teores de proteínas são bem mais limitadas quando comparadas com o teor de gordura (Fonseca e Santos, 2007). Variações nos teores de proteínas são determinantes do rendimento industrial na fabricação de queijos e outros lácteos dependentes de concentrações adequadas de 
caseína na matéria-prima (Lindmark-Mansson et al., 2003). O teor de extrato seco desengordurado apresentou redução entre os anos de 2002 e 2007, e em 2008 apresentou uma reação de aumento (Fig. 4). Comparando-se os anos de 2002 e 2008, observa-se que praticamente não houve diferença entre os resultados para os teores médios de gordura e de extrato seco desengordurado. No entanto, nota-se um aumento no teor de proteína para o mesmo período.

Tabela 4. Resultados anuais médios de teor de extrato seco desengordurado (ESD) do leite captado por uma indústria de laticínios de Minas Gerais, no período de 2002 a 2008, em conformidade com os padrões legais da IN 51

\begin{tabular}{ccccccccccc}
\hline \multirow{3}{*}{ Ano } & \multicolumn{9}{c}{ ESD } \\
\cline { 2 - 11 } & $\begin{array}{c}\text { Captação média } \\
\text { (litros/produtor/mês) }\end{array}$ & Média & $\mathrm{N}$ & $\%$ & $\begin{array}{c}\text { Captação média } \\
\text { (litros/produtor/mês) }\end{array}$ & Média & $\mathrm{N}$ & $\%$ & $\mathrm{~N}$ \\
\hline 2002 & 4871 & 8,26 & $268^{\mathrm{a}}$ & 5,12 & 5760 & 8,84 & $4963^{\mathrm{a}}$ & 94,88 & 5231 \\
2003 & 6742 & 8,25 & $865 \mathrm{~b}$ & 10,32 & 5893 & 8,80 & $7518 \mathrm{~b}$ & 89,68 & 8383 \\
2004 & 7879 & 8,27 & $566 \mathrm{c}$ & 7,14 & 5978 & 8,84 & $7358 \mathrm{c}$ & 92,86 & 7924 \\
2005 & 9791 & 8,23 & $650 \mathrm{ce}$ & 7,74 & 7539 & 8,83 & $7747 \mathrm{ce}$ & 92,26 & 8397 \\
2006 & 7849 & 8,26 & $976 \mathrm{~b}$ & 10,41 & 6536 & 8,79 & $8403 \mathrm{~b}$ & 89,59 & 9379 \\
2007 & 6436 & 8,24 & $1797 \mathrm{~d}$ & 17,29 & 6086 & 8,74 & $8594 \mathrm{~d}$ & 82,71 & 10391 \\
2008 & 7434 & 8,23 & $841 \mathrm{e}$ & 7,98 & 6997 & 8,83 & $9697 \mathrm{e}$ & 92,02 & 10538 \\
Total & 7285 & 8,25 & 5963 & 9,90 & 6455 & 8,81 & 54280 & 90,10 & 60243 \\
\hline
\end{tabular}

Valores seguidos de letras minúsculas distintas na coluna indicam diferença estatisticamente significativa $(\mathrm{P} \leq 0,05)$, pelo teste do qui-quadrado.
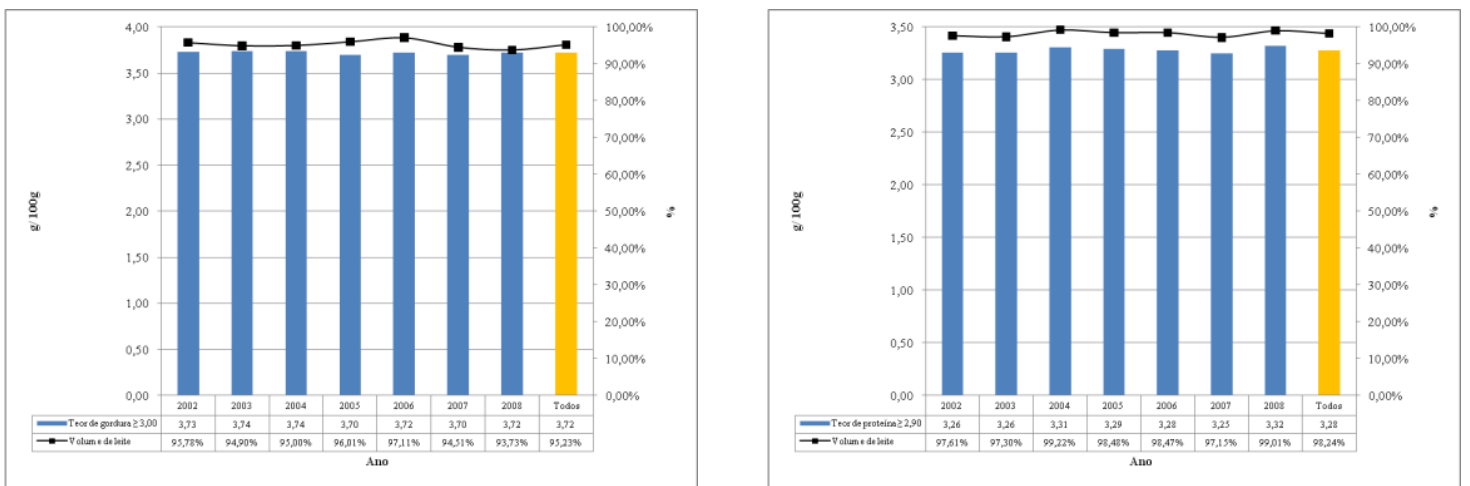

Figura 3. Volume percentual anual de leite captado por uma indústria de Minas Gerais, no período de 2002 a 2008, com valores médios de teor de gordura e de proteína, em conformidade com os padrões legais da IN 51.

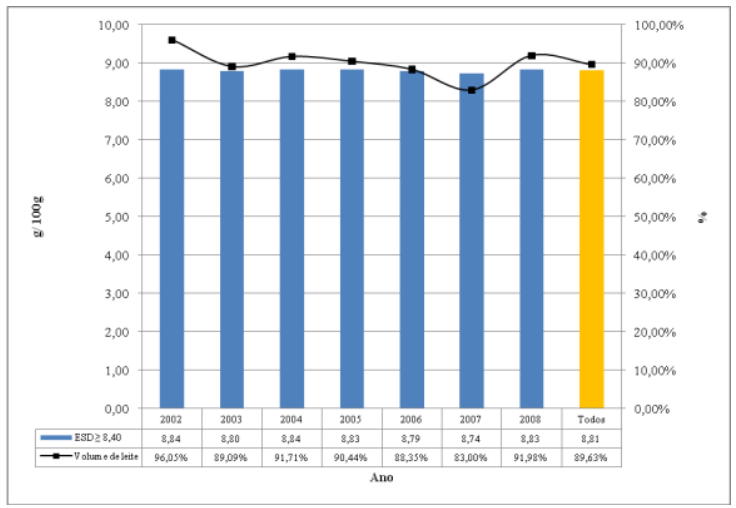

Figura 4. Volume percentual anual de leite captado por uma indústria de Minas Gerais, no período de 2002 a 2008, com valores médios de teor de extrato seco desengordurado, em conformidade com os padrões legais da IN 51 para 2008. 
O aumento do teor de sólidos do leite é uma condição essencial para a indústria que busca melhorar o seu rendimento de fabricação e, consequentemente, a sua competitividade junto aos mercados nacional e internacional de lácteos. No entanto, esse é um parâmetro de difícil manipulação em curto prazo e que envolve várias estratégias na área de gestão e produção para se obter o efeito desejado. Essas estratégias passam por políticas de orientação técnica, de melhoramento genético das raças, de incentivo no uso de tecnologias na área de nutrição que visam minimizar os efeitos das variações climáticas sobre a produção de alimentos e, por fim, de garantia econômica para a obtenção de um leite com os teores mínimos exigidos pela indústria, ao longo de todo o ano. Percebe-se que se trata de questão complexa que envolve a participação de todos os elos da cadeia produtiva do leite, pública e privada, e que não pode ser resolvida em curto espaço de tempo. Entretanto, para que o Brasil possa tornar-se mais competitivo e um grande exportador de lácteos, essas ações devem ser iniciadas tão logo quanto possível, ainda que em caráter regional.

\section{CONCLUSÕES}

As variações sazonais influenciaram a qualidade do leite cru refrigerado de tanques refrigeradores. A sazonalidade influenciou os teores percentuais de gordura e proteína do leite, e, na época das águas, a CCS e a CBT podem ter contribuído para a redução dos teores sólidos totais do leite. A implantação de um sistema de pagamento por qualidade do leite ao produtor melhorou os índices de qualidade da matéria-prima, especialmente a CBT do leite do tanque. A determinação de uma coleta seletiva do leite por qualidade entre fazendas pode ser viável economicamente e contribuir para maior competitividade das indústrias de laticínios no país.

\section{REFERÊNCIAS}

ALVIM, R.S.; MARTINS, M.C.; MUSTEFAGA, P.S. Desempenho da cadeia produtiva do leite no Brasil - visão dos produtores. In: DUARTE, V. (Ed.). O agronegócio do leite e políticas públicas para o seu desenvolvimento sustentável. 1.ed. Juiz de Fora: Embrapa Gado de Leite, 2002. p.195-204.
BRASIL. Instrução normativa n.51, de 18 de setembro de 2002. Regulamentos Técnicos de Produção, Identidade e Qualidade do Leite tipo $A$, do Leite tipo $B$, do Leite tipo $C$, do Leite Pasteurizado e do Leite Cru Refrigerado e o Regulamento Técnico da Coleta de Leite Cru Refrigerado e seu Transporte a Granel. Brasília, DF: Ministério da Agricultura, Secretária de Inspeção de Produto Animal. Publicado no Diário Oficial da União de 20/09/2002, Seção 1, p.13, 2002.

GALTON, D.M.; PETERSSON, L.G.; MERILL, W.G. Effects of premilking udder preparation practices on bacterial counts in milk and on teats. J. Dairy Sci., v.69, p.260-266, 1986.

GIGANTE, M.L.; COSTA, M.R. Influência das Células Somáticas nas Propriedades Tecnológicas do Leite e Derivados. In: CONGRESSO BRASILEIRO DE QUALIDADE DO LEITE, 3., 2008. Recife, Anais... Recife: CCS Gráfica e Editora, 2008. p.351.

INTERNATIONAL IDF Standard 141C:2000: Whole milk - determination of milkfat, protein and lactose content. Guidance on the operation of mid-infrared instruments. Brussels, 2000. 15f.

INTERNATIONAL IDF Standard 148A:1995: Milk - Enumaration of somatic cell. Brussels, 1995 (a). 8f.

LINDMARK-MANSSON，H.; FONDÉN， R.; PETTERSSON, H.E. Composition of Swedish dairy milk. Int. Dairy J., v.13, p.409-425, 2003.

MACHADO, P.F. Pagamento do leite por qualidade. In: CONGRESSO BRASILEIRO DE QUALIDADE DO LEITE, 3., Recife, 2008. Recife: CCS Gráfica e Editora, 2008. p.373.

MENDONÇA, A.H.; CERQUEIRA, M.M.O.P.; CAMARGOS, C.R.M. et al. Qualidade físicoquímica de leite cru resfriado: comparação de diferentes procedimentos e locais de coleta. In: CONGRESSO NACIONAL DE LATICÍNIOS, 18., 2001, Juiz de Fora. Anais... Juiz de Fora: Templo. 2001. p.276-282.

REIS, R.B.; GLÓRIA, J.R.; VIEIRA, L.R.; FARIA, B.N. Manipulação da qualidade do leite pela nutrição da vaca. In: Simpósio do Agronegócio do Leite: Produção e Qualidade, 1., Belo Horizonte, Escola de Veterinária da UFMG, 2004. 
SAMPAIO, I.B.M. Estatística aplicada à experimentação animal. Belo Horizonte: Fundação de Ensino e Pesquisa em Medicina Veterinária e Zootecnia, 2002. 221p.

SANTOS, M.V.; FONSECA, L.F.L. Estratégias para controle de mastite $e$ melhoria na qualidade do leite: contagem de células somáticas e o efeito da mastite sobre a qualidade do leite. 1.ed. Barueri: Manole, 2007. 314p.

SOUZA, M.J.H.; RIBEIRO, A.; LEITE, F.P. Balanço hídrico e caracterização climática de Guanhães, Nova Era e Rio Doce. In: CONGRESSO BRASILEIRO DE AGROMETEOROLOGIA, 13., 2003, Santa Maria. Anais... Santa Maria, RS: Sociedade Brasileira de Agrometeorologia, 2003. v.1. p.131-132.
SOUZA, M.J.H.; RIBEIRO, A.; LEITE, H.G. et al. Relação entre disponibilidade hídrica e produtividade do eucalipto em diferentes idades, em Guanhães, Minas Gerais. Rev. Bras. Eng. Agric. Amb., v.10, p.629-638, 2006.

TONELLO, K.C.; DIAS, H.C.T.; SOUZA, A.L. et al. Diagnóstico hidroambiental da bacia hidrográfica da Cachoeira das Pombas, município de Guanhães, MG, Brasil. Ambi-Agua, v.4, p.156-168, 2009.

WONG, A.C. Biofilms in food processing environments. J. Dairy Sci., v.81, p.2765-2770, 1998. 